Research Article

\title{
Synthesis of Acidic Heterogeneous Catalysts with High Stability Based on Graphene Oxide/Activated Carbon Composites for the Esterification of Lactic Acid
}

\author{
Thu Ha Thi Vu $\mathbb{D}^{1},{ }^{1}$ Manh Ha Nguyen $\mathbb{D}^{1},{ }^{1,2}$ and Minh Dang Nguyen $\mathbb{D}^{1}$ \\ ${ }^{1}$ National Key Laboratory for Petrochemical and Refinery Technologies, Hanoi, Vietnam \\ ${ }^{2}$ Faculty of Chemical Technology, Hanoi University of Industry, Hanoi, Vietnam \\ Correspondence should be addressed to Thu Ha Thi Vu; ptntd2004@yahoo.fr
}

Received 21 February 2019; Revised 3 May 2019; Accepted 21 May 2019; Published 4 June 2019

Guest Editor: Nguayen Van Noi

Copyright (C) 2019 Thu Ha Thi Vu et al. This is an open access article distributed under the Creative Commons Attribution License, which permits unrestricted use, distribution, and reproduction in any medium, provided the original work is properly cited.

In this article, acidic heterogeneous catalysts based on graphene oxide and sulfonated biochar were prepared, characterized, and used for lactic acid esterification to form ethyl lactate. Graphene oxide was supported on activated carbon (GO/AC) to more easily filter the catalyst from the reactants. The catalysts were characterized by such methods as XRD, FT-IR, SEM, BET, and the acidbase titration. Catalytic activity was evaluated through the esterification of lactic acid. As a result, the activity of the catalysts decreased in the following order: graphene oxide $>$ sulfonated biochar $\approx \mathrm{GO} / \mathrm{AC}>>$ activated carbon. In addition, the GO/AC catalyst showed good stability with an unchanged yield from the $3^{\text {rd }}$ to the $6^{\text {th }}$ recycling test. These results suggest potential applications for new acidic heterogeneous catalysts based on graphene oxide and sulfonated biochar that could replace homogeneous acids in the future.

\section{Introduction}

Ethyl lactate is an ecofriendly solvent with valuable properties such as low volatility, high biodegradability, and low toxicity. Ethyl lactate is used as a "green" solvent in different fields such as organic synthesis, pharmaceuticals, coatings, printing, food, and perfume additives [1]. Ethyl lactate has many positive characteristics and can replace traditional solvents originating from petroleum.

Ethyl lactate is a product of lactic acid esterification in the presence of an acidic catalyst. Acidic homogeneous catalysts, such as $\mathrm{H}_{2} \mathrm{SO}_{4}$ and $\mathrm{HCl}$, have been used for esterification. However, acidic homogeneous catalysts cannot be recycled and have to be neutralized, thereby complicating the process. To overcome their disadvantages, heterogeneous catalysts have been used in esterifications despite them having lower activity than homogeneous catalysts.

Over the years, many solid acid catalysts for lactic acid esterification such as Preysler [2], $\mathrm{K}_{3} \mathrm{PW}_{12} \mathrm{O}_{40}$ [3], and Amberlyst ionic resins [4-7] have been investigated. Among these catalysts, solid acid catalysts based on sulfonated carbon have attracted the attention of many scientists. These catalysts are synthesized by the sulfonation of carbonated products such as starch, cellulose, and glucose [8]. With the abundance of such acidic functional groups as $-\mathrm{SO}_{3} \mathrm{H}$ and $-\mathrm{COOH}$ on their surface, these catalysts have been applied in esterification [9-11] and transesterification [12, 13] reactions. However, during the reaction, $-\mathrm{SO}_{3} \mathrm{H}$ groups leach into the reactive medium, reducing catalytic activity [14].

Recently, graphene and graphene oxide (GO) have earned more attention from researchers due to their high stabilities in the liquid phase and their high resistance in the acidic medium. Moreover, many of their applications have been implemented, such as energy storage, electronic devices, optoelectronics, sensors, and catalysis [15-17]. Graphene oxide was synthesized by the oxidation of graphite forming acidic functional groups such as $-\mathrm{SO}_{3} \mathrm{H}$ and carboxylic acid on the surface of the material. Due to these functional groups, graphene oxide has been used as an acidic catalyst in organic synthesis, such as in the cellulose 
hydrolysis reaction [18]; the dehydration and etherification of fructose, xylose, and inulin [19, 20]; the etherification of HMF [21]; the esterification of levulinic acid with alcohol [22]; the esterification of glycerol and acetic acid [23]; and biodiesel synthesis [24]. The results showed that the catalytic activity of graphene oxide was good for these reactions. For example, using graphene oxide as catalyst, Wei et al. reported that the yield of forming ethyl acetate was $93.5 \%$ for esterification between acetic acid and ethanol, higher than the yield when using the homogeneous catalyst $\mathrm{H}_{2} \mathrm{SO}_{4}$ [25]. Samir Kundu and Basudeb Basu used and reused GO as a catalyst for 2-aminopyridine, acetophenone, and thiophenol synthesis. The conversion was quite stable with a value of $84 \%$ and $80 \%$ for the $1^{\text {st }}$ and $4^{\text {th }}$ cycles, respectively [26].

Graphene oxide is a potentially acidic heterogeneous catalyst with good solubility in aqueous solutions (or polar solvents) because it includes many oxygen-rich functional groups $(-\mathrm{OH},-\mathrm{COOH},-\mathrm{CHO}$, etc.), which are very highly hydrophilic [17]. However, this property makes it difficult to separate the graphene oxide catalyst from the reaction mixture. Therefore, the separation of graphene oxide from the reaction mixture usually requires a high-speed centrifugation process instead of normal filtrations or vacuum extractions [17, 21, 23, 24].

To solve this problem, graphene oxide should be supported on a solid with a high surface area, not only limiting its "high solubility" but also avoiding the "leaching" of graphene oxide into the reaction medium. In this article, the synthesis of solid catalysts based on sulfonated biochar and graphene oxide was studied. Graphene oxide was supported on activated carbon to more easily filter the catalysts from the reactants. Their catalytic activities were tested by demonstrating lactic acid esterification from ethyl lactate.

\section{Materials and Methods}

2.1. Materials. Pine sawdust, taken from Ninh Binh province, Vietnam, was crushed, sieved, and collected. All sawdust particles are in the range of 0.5 to $0.85 \mathrm{~mm}$ in diameter. Then, the collected sawdust was dried at $105^{\circ} \mathrm{C}$ for $2 \mathrm{~h}$. Commercially activated carbon, made from coconut shells in Vietnam, was washed with distilled water, dried at $105^{\circ} \mathrm{C}$, and finally crushed. Expanded graphite powder (<45 $\mu \mathrm{m}, 99.9995 \%), \mathrm{NaNO}_{3}$ ( $\left.\geq 99 \%\right), \mathrm{KMnO}_{4}$ ( $\left.\geq 99 \%\right), \mathrm{H}_{2} \mathrm{O}_{2}$ (30\%), $\mathrm{HCl}(37 \%), \mathrm{H}_{2} \mathrm{SO}_{4}(95-98 \%)$, lactic acid $85 \%$, and ethanol (99.95\%) were all purchased from Sigma-Aldrich (Singapore). All experiments were conducted using deionized water.

\subsection{Synthesis of Graphene Oxide Supported on Activated} Carbon (GO/AC). Graphene oxide synthesis was conducted using the modified method of Hummers [27]. GO after synthesis is dispersed in water with a concentration of $5.0 \mathrm{mg} \cdot \mathrm{mL}^{-1}$. GO is dispersed on AC support by the dry impregnation method: $100 \mathrm{~mL}$ of the supension was stirred into $5.000 \mathrm{~g}$ of $85^{\circ} \mathrm{C}$-dried $\mathrm{AC}$ in a $250 \mathrm{~mL}$ glass beaker at room temperature for $5 \mathrm{~h}$. Then, the mixture was dried at $85^{\circ} \mathrm{C}$ for $48 \mathrm{~h}$. Then, it was cooled off in a desiccator. Finally, we obtained $5.495 \mathrm{~g}$ of GO/AC catalyst with a weight ratio of GO to AC of $1: 10$. The efficiency on the supporting process was at $99.91 \%$.

2.3. Synthesis of Sulfonated Biochar. The synthesis followed two processes:

(i) Carbonation: $40 \mathrm{~g}$ of pine sawdust was carbonated in a furnace under an $\mathrm{N}_{2}$ environment, at $400^{\circ} \mathrm{C}$ for $5 \mathrm{~h}$ (heating rate of $10^{\circ} \mathrm{C} / \mathrm{min}$ ). The product obtained was denoted as biochar.

(ii) Sulfonation: $15 \mathrm{~g}$ of obtained biochar was stirred at $150^{\circ} \mathrm{C}$ in $300 \mathrm{ml}$ of $98 \% \mathrm{H}_{2} \mathrm{SO}_{4}$ solution in a threeneck glass flask of $500 \mathrm{ml}$ for $15 \mathrm{~h}$. The reaction system was cooled and slowly diluted with $1 \mathrm{~L}$ of distilled water. Then, hot distilled water $\left(80^{\circ} \mathrm{C}\right)$ was used to wash the filtered mixture until the sulfate ion disappeared (checked by $10 \% \mathrm{BaCl}_{2}$ solution). The solid was dried at $105^{\circ} \mathrm{C}$ for $8 \mathrm{~h}$ to obtain the final product-sulfonated biochar catalyst.

2.4. Catalyst Characterization. Sample morphology was observed by scanning electron microscopy (SEM) using an S-4800 microscope (Hitachi, Japan). The specific surface area of the catalysts was measured by BET Micromeritics 201-A. The infrared spectrum of the samples, in the wavelength range of $400-4000 \mathrm{~cm}^{-1}$, was measured on a Tensor 27Bruker FTIR Spectrometer. XRD patterns of the catalysts were measured on a D8 Advance (Bruker) apparatus. A shaker and $\mathrm{pH}$ meter were used for titration. The acidic content $\left(-\mathrm{SO}_{3} \mathrm{H}\right)$ of all catalysts was determined by an acidbase titration method [28]. For example, a suspension which contains $1 \mathrm{~g}$ of catalyst and $50 \mathrm{~mL}$ of $1 \mathrm{M} \mathrm{NaCl}$ solution in a $250 \mathrm{~mL}$ Erlenmeyer flask was shaken at a speed of $130 \mathrm{rpm}$ for 4 hours. Next, the mixture was filtered. Then, the liquid was titrated by $0.1 \mathrm{M} \mathrm{NaOH}$ solution.

The $-\mathrm{SO}_{3} \mathrm{H}$ content per $1 \mathrm{~g}$ of catalyst is calculated by the following formula:

$$
\mathrm{N}_{-\mathrm{SO}_{3} \mathrm{H}}=\frac{(0.1 \times V)}{1} \times \frac{50}{20}\left(\mathrm{mmol} \cdot \mathrm{g}^{-1}\right)
$$

where $V$ is the volume of used $\mathrm{NaOH}$ solution $(\mathrm{mL})$ and $\mathrm{N}_{-\mathrm{SO}_{3} \mathrm{H}}$ is the $-\mathrm{SO}_{3} \mathrm{H}$ content per $1 \mathrm{~g}$ of catalyst.

2.5. Catalytic Tests. The activity of the catalysts was evaluated through the esterification reaction between lactic acid $50 \%$ (obtained from $85 \%$ lactic acid solution by the dilution) and ethanol (mole ratio $1: 4$ ) at $82^{\circ} \mathrm{C}$ [29]. The weight ratios of the sulfonated biochar and GO catalysts to lactic acid are $5 \%$ and $1 \%$, respectively. Because of the difficulty in filtering, the weight ratio of GO catalyst cannot be not higher than $1 \%$. To make it easier to compare the catalytic activity between $\mathrm{GO}$ and $\mathrm{GO} / \mathrm{AC}$, the contents of $\mathrm{GO}$ included in the GO/AC catalyst are equal to that of the GO catalyst.

Ethyl lactate product was determined by the internal standardization method on an Agilent 7890A gas 
chromatograph equipped with an FID. The yield of ethyl lactate was calculated by the following formula:

$$
\text { ethyl lactate yield }(\%)=\frac{n_{\text {ethyl lactate }}}{n_{\text {ethyl lactate }}^{\mathrm{o}}} \times 100 \text {, }
$$

where $n_{\text {ethyl lactate }}$ is the real mole of ethyl lactate that is determined by the gas chromatography test and $n_{\text {ethyllactate }}^{\mathrm{o}}$ is the theory mole of ethyl lactate that is a value with $100 \%$ conversion of lactic acid.

2.6. Recycling Catalyst Tests. After completion of the reaction, the GO/AC and sulfonated biochar catalysts were filtered and washed three times by using hot distilled water $\left(\geq 80^{\circ} \mathrm{C}\right.$ ). Then, the catalysts were dried at $105^{\circ} \mathrm{C}$ for $8 \mathrm{~h}$. The recycled catalysts were reused for lactic acid esterification.

\section{Results and Discussion}

3.1. Catalyst Characterization. The structural properties of sulfonated biochar, activated carbon, graphene oxide, and GO/AC determined by the XRD method are shown in Figure 1. There is a broad peak at $20^{\circ}$ to $30^{\circ}$ of 2-theta-scale; these data mean that the sulfonated biochar catalyst has an amorphous structure [10]. There is a specific peak observed at $11^{\circ}$ of 2 -theta-scale (corresponding to the crystal of graphene oxide) for both graphene oxide and the GO/AC catalysts [22]. However, in the case of GO/AC catalyst, the peak is much lower in intensity. This result confirmed the successful synthesis of graphene oxide from expanded graphite and indicated that there was interaction between the graphene oxide and activated carbon in the GO/AC catalyst.

Figure 2 shows the SEM images of the sulfonated biochar, activated carbon, graphene oxide, and GO/AC catalysts. The results indicate a porous structure with large capillaries, a solid structure, and a transparently layered structure for the sulfonated biochar (Figure 2(a)), activated carbon (Figure 2(b)), and graphene oxide (Figure 2(c)), respectively. Figure $2(\mathrm{~d})$ shows that the GO/AC catalyst shows a "sandwich" structure in which the activated carbon is surrounded by graphene oxide layers, proving that the $\mathrm{GO} / \mathrm{AC}$ catalyst was successfully prepared.

The FT-IR spectra of the catalysts are shown in Figure 3. In the infrared spectra of sulfonated biochar, graphene oxide, and GO/AC catalysts, there are characteristic vibration bands of $-\mathrm{OH}$ bonding and the $\mathrm{C}=\mathrm{O}$ group, including the $-\mathrm{COOH}$ functional group at $3416,3387,3444 \mathrm{~cm}^{-1}$ and $1709,1698,1694 \mathrm{~cm}^{-1}$, respectively. There are also valence vibrations of $\mathrm{S}=\mathrm{O}$ bonding included in the $-\mathrm{SO}_{3} \mathrm{H}$ group at 1040,1059 , and $1108 \mathrm{~cm}^{-1}[10,23]$. Meanwhile, valence vibrations of $\mathrm{S}=\mathrm{O}$ are not observed in the case of the activated carbon catalyst, indicating that there is no presence of $-\mathrm{SO}_{3} \mathrm{H}$ groups in the activated carbon structure.

Specific surface areas of the catalysts are presented in Table 1. The results showed that the areas of the catalysts are quite high (over $400 \mathrm{~m}^{2} \mathrm{~g}^{-1}$ ). Because of the filling of GO particles in the micropores of the activated carbon, there is a decrease in the specific surface area of the GO/AC in

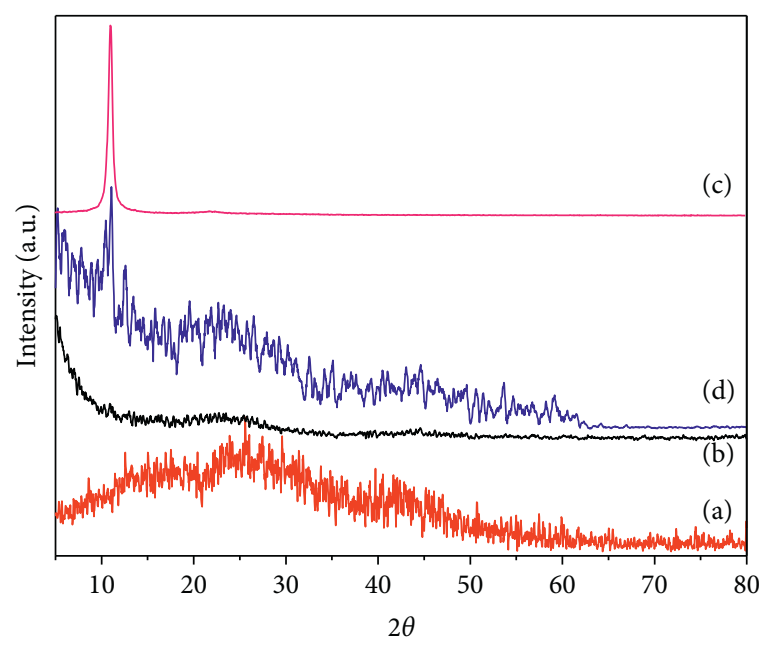

FIGURE 1: XRD patterns of sulfonated biochar (a), activated carbon (b), graphene oxide (c), and GO/AC (d).

comparison with the original activated carbon $\left(150.7 \mathrm{~m}^{2} \mathrm{~g}^{-1}\right.$ lower). However, after 6 cycles, there was a slight increase of $S_{\mathrm{BET}}$ of GO/AC $\left(49 \mathrm{~m}^{2} \mathrm{~g}^{-1}\right.$ higher $)$ in comparison with initial GO/AC. This can be explained by some reasons. Firstly, during the esterification, small amounts of GO may be removed from the surface of AC to the reaction medium. Moreover, the specific surface area of AC is higher than that of GO.

Table 1 also presents the sulfonic acid group $\left(-\mathrm{SO}_{3} \mathrm{H}\right)$ contents of the catalysts. The results showed that the sulfonic acid group contents were $1.14 \mathrm{mmol} \cdot \mathrm{g}^{-1}, 0.35 \mathrm{mmol} \cdot \mathrm{g}^{-1}$, and $0.92 \mathrm{mmol} \cdot \mathrm{g}^{-1}$ for sulfonated biochar, GO/AC, and GO catalysts, respectively. There was not much difference in sulfonic acid content between GO and sulfonated biochar catalysts.

3.2. Catalytic Tests. Figure 4 presents the ethyl lactate yield related to the reaction time for all the catalysts. All the tests were carried out under the same conditions.

According to the results presented in Figure 4, it can be seen that the catalytic activity decreases in the following order: graphene oxide $(51.0 \%)>$ sulfonated bio-char $(37.0 \%) \approx \mathrm{GO} / \mathrm{AC}(35.4 \%)>>$ activated carbon $(20.0 \%)$ after $420 \mathrm{~min}$ of reaction time. This order seems to be related to the sulfonic acid content and dispersion properties of each catalyst. Although the sulfonic acid content of sulfonated biochar and graphene oxide is similar $\left(1.14 \mathrm{mmol} \cdot \mathrm{g}^{-1}\right.$ and $0.92 \mathrm{mmol} \cdot \mathrm{g}^{-1}$, respectively), graphene oxide catalysts showed much higher activity than the sulfonated biochar catalysts, which may be due to the higher dispersion of graphene oxide in aqueous medium compared to sulfonated biochar. As previously mentioned, the dispersion of graphene oxide was high as a "pseudo-homogeneous" catalyst because there is the presence of numerous hydrophilic functional groups $(-\mathrm{COOH},-\mathrm{OH}$, and $-\mathrm{CHO})$ in its structure. Consequently, it is easy for the "accessible sulfonic groups" of graphene oxide catalyst to be active in the reaction that leads to an increase in ethyl lactate yield. However, its 


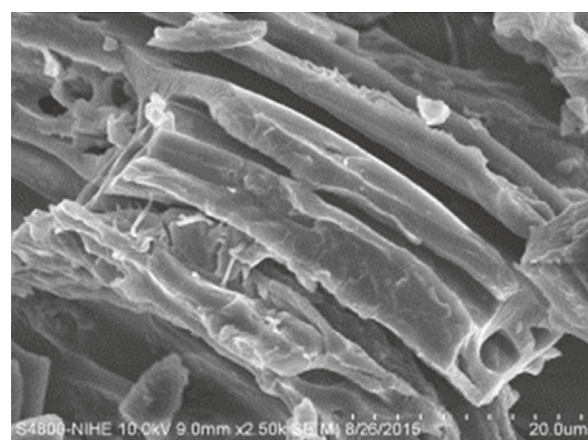

(a)

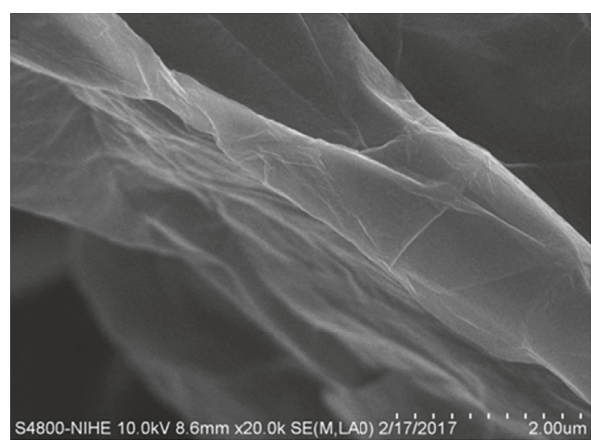

(c)

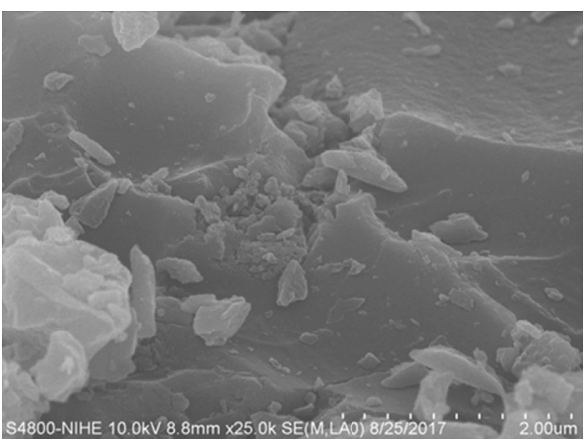

(b)

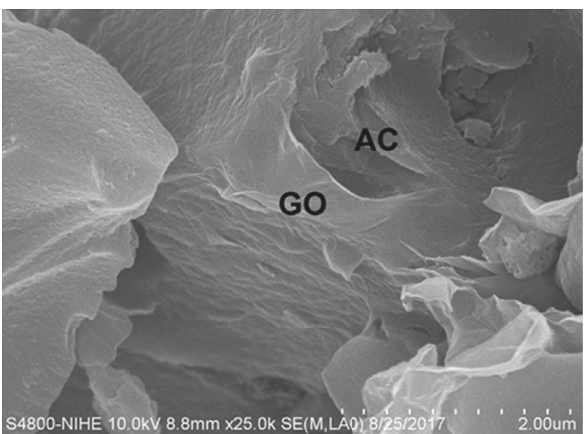

(d)

FIGURE 2: SEM images of sulfonated biochar (a), activated carbon (b), graphene oxide (c), and GO/AC (d).

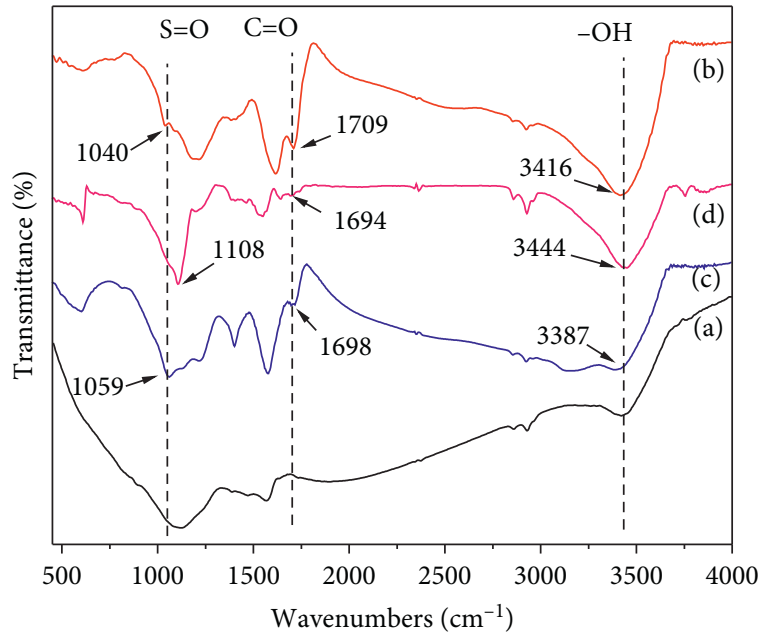

FIGURE 3: FT-IR spectra of activated carbon (a), sulfonated biochar (b), graphene oxide (c), and GO/AC (d).

drawback is a difficulty with filtering or taking the catalyst away from the reactants. Hence, we only used $1 \%$ by weight of graphene oxide in order to be able to analyze ethyl lactate by gas chromatography.

In the case of the sulfonated biochar and $\mathrm{GO} / \mathrm{AC}$ catalysts, their catalytic activities are similar, although the $-\mathrm{SO}_{3} \mathrm{H}$ content of the $\mathrm{GO} / \mathrm{AC}$ catalyst is only $0.35 \mathrm{mmol} \cdot \mathrm{g}^{-1}$, which is three times lower than that of the sulfonated biochar catalyst. This result confirms that a good combination of graphene oxide and activated carbon can serve as a catalyst for the esterification of lactic acid. As shown in
TABLE 1: Specific surface areas and sulfonic acid group $\left(-\mathrm{SO}_{3} \mathrm{H}\right)$ content of the catalysts.

\begin{tabular}{lcc}
\hline Catalysts & $\begin{array}{c}\mathrm{S}_{\mathrm{BET}} \\
\left(\mathrm{m}^{2} \cdot \mathrm{g}^{-1}\right)\end{array}$ & $\begin{array}{c}-\mathrm{SO}_{3} \mathrm{H} \text { content } \\
\left(\mathrm{mmol} \mathrm{g}^{-1}\right)\end{array}$ \\
\hline $\begin{array}{l}\text { Sulfonated biochar } \\
\text { Sulfonated biochar after } 4 \\
\text { cycles of reaction }\end{array}$ & 423.4 & 1.14 \\
Activated carbon & - & 0.64 \\
Graphene oxide & 721.1 & 0 \\
GO/AC & 215.9 & 0.92 \\
GO/AC after 6 cycles of reaction & 570.3 & 0.35 \\
\hline
\end{tabular}

Table 1, there is no $-\mathrm{SO}_{3} \mathrm{H}$ group included in the structure of activated carbon, explaining why this catalyst showed the lowest catalytic activity.

3.3. Recycling Tests of Catalysts. The GO/AC and sulfonated biochar catalysts were recycled six and four times, respectively. Ethyl lactate yields of each recycling test are presented in Figure 5. Figure 5(a) noted that the activity of $\mathrm{GO} / \mathrm{AC}$ catalyst decreased slowly from the $1^{\text {st }}$ to the $3^{\text {rd }}$ cycle, respectively, from $35.4 \%$ to $30.3 \%$ after a reaction time of $420 \mathrm{~min}$, that means $14.4 \%$ of reduction, and it seem to be unchanged from $3^{\text {rd }}$ to $6^{\text {th }}$ cycles, the percentage of decrease is only $3.3 \%$. In the same way, with sulfonated biochar catalyst (see Figure 5(b)), the activity was decreased from $37.0 \%$ in the $1^{\text {st }}$ cycle to $26.1 \%$ in the $4^{\text {th }}$ cycle, that is equal to $29.5 \%$ of reduction. Hence, stability of GO/AC is much higher than sulfonated biochar catalyst. 


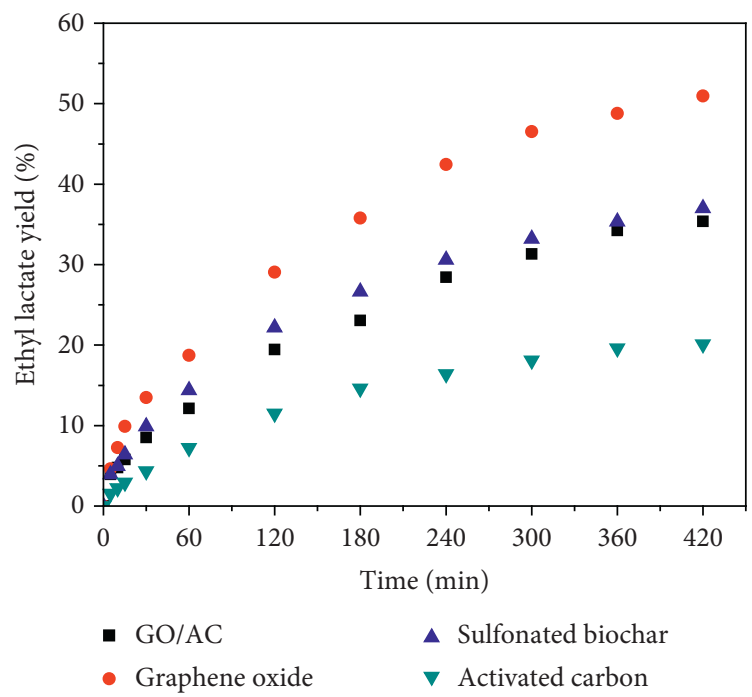

FIGURE 4: Ethyl lactate yield versus reaction time.

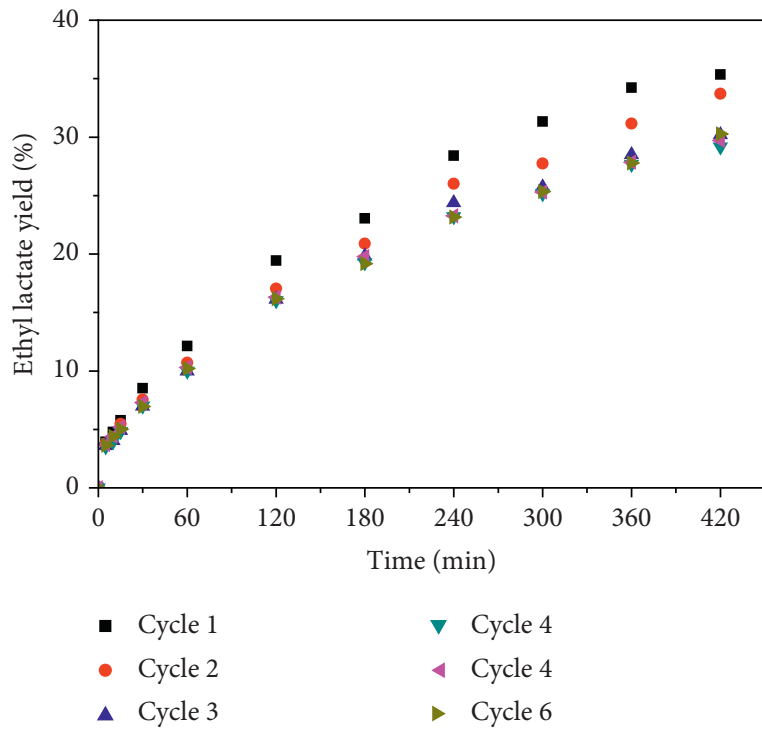

(a)

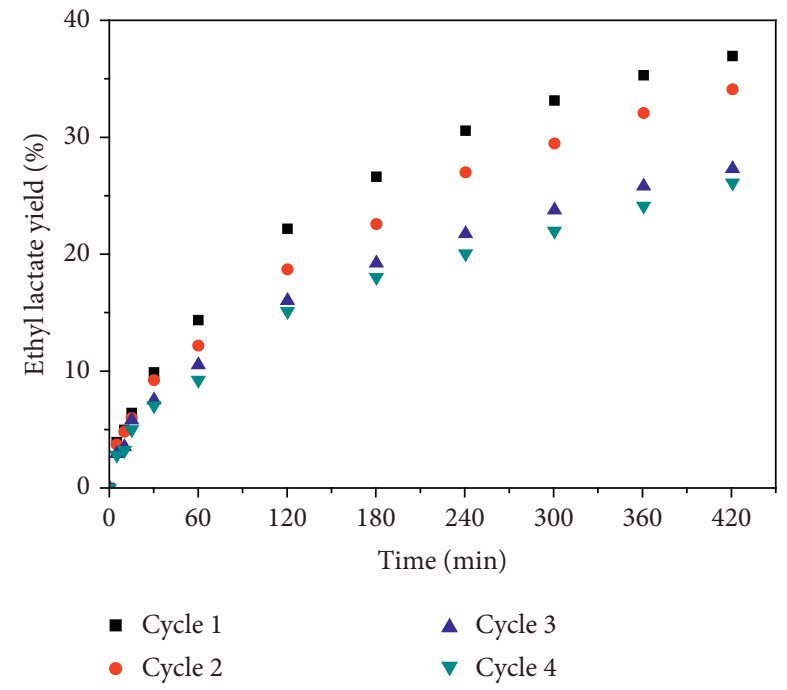

(b)

FIgure 5: Test of recycled GO/AC (a) and sulfonated biochar (b) catalysts.

The $-\mathrm{SO}_{3} \mathrm{H}$ contents presented in Table 1 confirm that the durability of GO/AC is higher than sulfonated biochar catalyst. In details, the functional group in $\mathrm{GO} / \mathrm{AC}$ reduced from $0.35 \mathrm{mmol} \cdot \mathrm{g}^{-1}$ to $0.29 \mathrm{mmol} \cdot \mathrm{g}^{-1}$ that means $17.1 \%$ of decrease after 6 cycles. However, the value of sulfonated biochar is near 2.6 times higher, $43.9 \%$, after 4 cycles. The result also confirms that in the active phase, GO was well dispersed and attached onto the support, activated carbon.

In addition to the strong attachment of graphene oxide onto activated carbon, it seems that the sulfonic group $-\mathrm{SO}_{3} \mathrm{H}$ of the $\mathrm{GO} / \mathrm{AC}$ catalyst was more stable than that of the sulfonated bio-char. To explain this phenomenon, FT-IR spectra of 6-times recycled graphene oxide catalyst are presented in Figure 6. The FT-IR spectra of the GO/AC after
6 cycles of reaction also showed vibrations at $3423 \mathrm{~cm}^{-1}$, $1705 \mathrm{~cm}^{-1}$, and $1080 \mathrm{~cm}^{-1}$ corresponding to the presence of the $-\mathrm{OH},-\mathrm{COOH}$, and $-\mathrm{SO}_{3} \mathrm{H}$ groups, respectively.

In our knowledge, there are some qualitative causes of the bond between GO and AC support. Firstly, the connection as esterification of the similar functional groups like carboxyl (-COOH) and hydroxyl (-OH) (see Figure 7), which present in both GO and AC surface [30], can contribute to the combination to become stronger. Moreover, $\mathrm{Ai}$ and Jiang [31] reported another explanation that both GO and $\mathrm{AC}$ include aromatic rings in their structure. It means that $\pi-\pi$ interactions may present when GO is coated on AC surface. As a result, the combination becomes better.

Because of some above results, GO/AC catalyst shows not only better catalytic activity but also higher stability than 


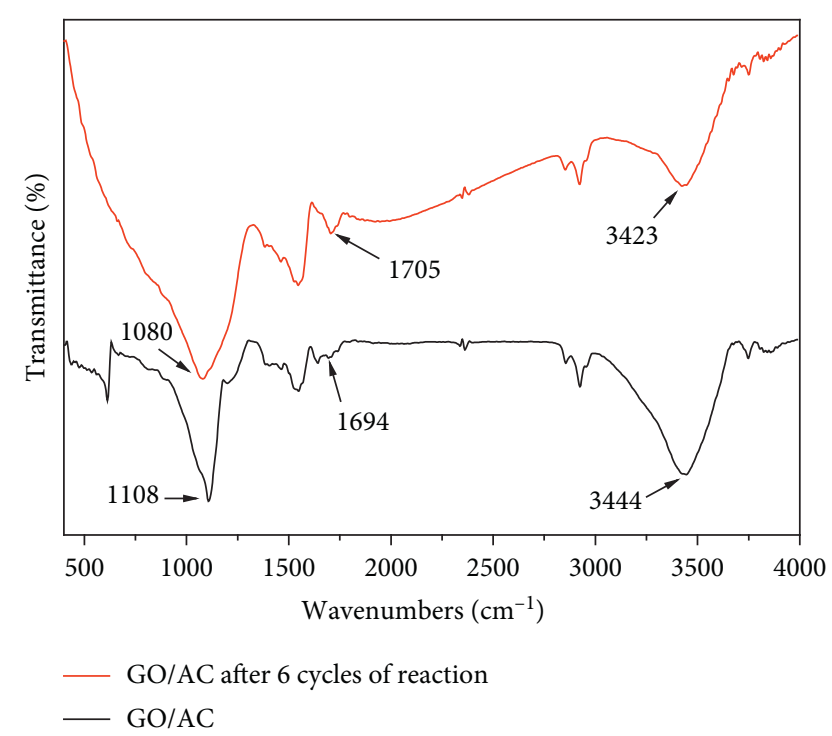

Figure 6: FT-IR spectra of GO/AC and GO/AC after 6 reaction cycles.

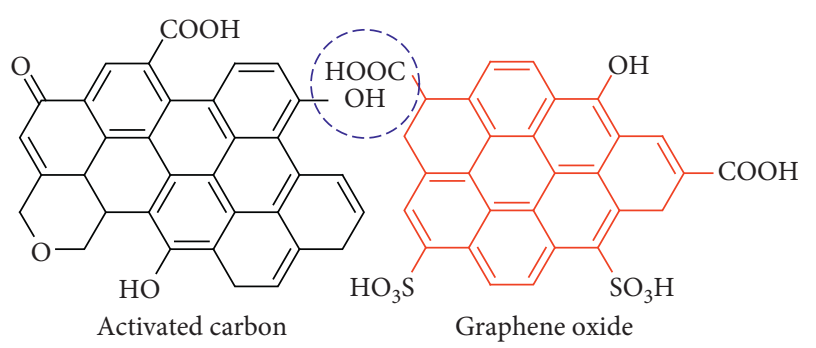

FIGURE 7: Self-esterification of activated carbon and graphene oxide.

sulfonated biochar in lactic acid esterification to form ethyl lactate. This catalyst demonstrates a combination of "solubility" of the active-phase graphene oxide and a high surface area as well as ease of separation of the activated carbon.

\section{Conclusions}

Graphene oxide, graphene oxide supported on activated carbon (GO/AC), and sulfonated biochar catalysts were synthesized and investigated as acidic heterogeneous catalysts for lactic acid esterification to form ethyl lactate. The catalytic activity of the catalysts is in the following order: graphene oxide $>$ sulfonated bio-char $\approx \mathrm{GO} / \mathrm{AC}>$ activated carbon. It seems that catalytic activities are related to the $-\mathrm{SO}_{3} \mathrm{H}$ content, especially the accessible $-\mathrm{SO}_{3} \mathrm{H}$ content. Among the catalysts, the GO/AC and sulfonated biochar catalysts showed similar activity with an approximate yield of $35 \%$ ethyl lactate after $420 \mathrm{~min}$ of reaction time. This catalytic activity of GO/AC is remarkable because of the presence of only $1 \%$ by weight GO as the active phase. In addition, the results of the recycled catalyst tests showed that the GO/AC catalytic activity was stable after the $3^{\text {rd }}$ cycle and reached a yield of $30.3 \%$ ethyl lactate after $420 \mathrm{~min}$ of reaction time. Under the same reaction conditions, the catalytic activities of sulfonated biochar decreased sharply with a decrease in ethyl lactate yield from $37.0 \%$ to $26.1 \%$ after four recycling times. The remarkable catalytic activity and stability of the GO/AC catalyst are explained by good dispersion, stability of partial esterification, and the $\pi-\pi$ interactions between active-phase graphene oxide and activated carbon. From the point of view of application, it is concluded that the GO/AC catalyst shows high potential as a catalyst for the esterification of lactic acid.

\section{Data Availability}

The data used to support the findings of this study are available from the corresponding author upon request.

\section{Conflicts of Interest}

The authors declare that they have no conflicts of interest.

\section{Acknowledgments}

The authors gratefully acknowledge the financial supports from the Project Management Unit of FIRST for this subproject through grant agreement no. 06/FIRST/2A/ KEYLABPRT.

\section{References}

[1] P. G. Jessop, "Searching for green solvents," Green Chemistry, vol. 13, no. 6, pp. 1391-1398, 2011.

[2] F. F. Bamoharram, M. M. Heravi, P. Ardalan, and T. Ardalan, "A kinetic study of the esterification of lactic acid by ethanol in the presence of Preyssler acid an eco-friendly solid acid catalyst," Reaction Kinetics, Mechanisms and Catalysis, vol. 100, no. 1, pp. 71-78, 2010.

[3] T. H. T. Vu, H. T. Au, T. H. T. Nguyen et al., "Esterification of lactic acid by catalytic extractive reaction: an efficient way to produce a biosolvent composition," Catalysis Letters, vol. 143, no. 9, pp. 950-956, 2013.

[4] Y. Zhang, L. Ma, and J. Yang, "Kinetics of esterification of lactic acid with ethanol catalyzed by cation-exchange resins," Reactive and Functional Polymers, vol. 61, no. 1, pp. 101-114, 2004.

[5] P. Delgado, M. T. Sanz, and S. Beltrán, "Kinetic study for esterification of lactic acid with ethanol and hydrolysis of ethyl lactate using an ion-exchange resin catalyst," Chemical Engineering Journal, vol. 126, no. 2-3, pp. 111-118, 2007.

[6] C. S. M. Pereira, S. P. Pinho, V. M. T. M. Silva, and A. E. Rodrigues, "Thermodynamic equilibrium and reaction kinetics for the esterification of lactic acid with ethanol catalyzed by acid ion-exchange resin," Industrial \& Engineering Chemistry Research, vol. 47, no. 5, pp. 1453-1463, 2008.

[7] O. Edidiong, S. Habiba, and E. Gobina, "Batch process esterification of lactic acid catalysed by cation-exchange resins for the production of environmental-friendly solvent," in Proceedings of the World Congress on Engineering and Computer Science. Lecture Notes in Engineering and Computer Science 2015, vol. II, pp. 623-628, WCECS, San Francisco, CA, USA, October 2015.

[8] S. Kang, J. Ye, and J. Chang, "Recent advances in carbonbased sulfonated catalyst: preparation and application," International Review of Chemical Engineering, vol. 5, no. 2, pp. 133-145, 2013. 
[9] T. Liu, Z. Li, W. Li, C. Shi, and Y. Wang, "Preparation and characterization of biomass carbon-based solid acid catalyst for the esterification of oleic acid with methanol," Bioresource Technology, vol. 133, pp. 618-621, 2013.

[10] W.-Y. Lou, Q. Guo, W.-J. Chen, M.-H. Zong, H. Wu, and T. J. Smith, "A highly active bagasse-derived solid acid catalyst with properties suitable for production of biodiesel," ChemSusChem, vol. 5, no. 8, pp. 1533-1541, 2012.

[11] M.-L. Tao, H.-Y. Guan, X.-H. Wang, Y.-C. Liu, and R.-F. Louh, "Fabrication of sulfonated carbon catalyst from biomass waste and its use for glycerol esterification," Fuel Processing Technology, vol. 138, pp. 355-360, 2015.

[12] M. Zhang, A. Sun, Y. Meng, L. Wang, H. Jiang, and G. Li, "Catalytic performance of biomass carbon-based solid acid catalyst for esterification of free fatty acids in waste cooking oil," Catalysis Surveys from Asia, vol. 19, no. 2, pp. 61-67, 2014.

[13] J. R. Kastner, J. Miller, D. P. Geller, J. Locklin, L. H. Keith, and T. Johnson, "Catalytic esterification of fatty acids using solid acid catalysts generated from biochar and activated carbon," Catalysis Today, vol. 190, no. 1, pp. 122-132, 2012.

[14] X.-Y. Liu, M. Huang, H.-L. Ma et al., "Preparation of a carbonbased solid acid catalyst by sulfonating activated carbon in a chemical reduction process," Molecules, vol. 15, no. 10, pp. 7188-7196, 2010.

[15] N. M. Julkapli and S. Bagheri, "Graphene supported heterogeneous catalysts: an overview," International Journal of Hydrogen Energy, vol. 40, no. 2, pp. 948-979, 2015.

[16] B. F. Machado and P. Serp, "Graphene-based materials for catalysis," Catalysis Science \& Technology, vol. 2, no. 1, pp. 54-75, 2012.

[17] S. Bykkam, K. V. Rao, C. S. Chakra, and T. Thunugunta, "Synthesis and characterization of graphene oxide and its antibacterial activity against Klebseilla and Staphylococus," International Journal of Advanced Biotechnology and Research, vol. 4, no. 1, pp. 1005-1009, 2013.

[18] X. Zhao, J. Wang, C. Chen, Y. Huang, A. Wang, and T. Zhang, "Graphene oxide for cellulose hydrolysis: how it works as a highly active catalyst?," Chemical Communications, vol. 50, no. 26, pp. 3439-3442, 2014.

[19] E. Lam, J. H. Chong, E. Majid et al., "Carbocatalytic dehydration of xylose to furfural in water," Carbon, vol. 50, no. 3, pp. 1033-1043, 2012.

[20] D. Mondal, J. P. Chaudhary, M. Sharma, and K. Prasad, "Simultaneous dehydration of biomass-derived sugars to 5hydroxymethyl furfural (HMF) and reduction of graphene oxide in ethyl lactate: one pot dual chemistry," RSC Advances, vol. 4, no. 56, pp. 29834-29839, 2014.

[21] H. Wang, Y. Wang, T. Deng, C. Chen, Y. Zhu, and X. Hou, "Carbocatalyst in biorefinery: selective etherification of 5hydroxymethylfurfural to 5,5' (oxy-bis(methylene)bis-2furfural over graphene oxide," Catalysis Communications, vol. 59, pp. 127-130, 2015.

[22] S. Zhu, C. Chen, Y. Xue, J. Wu, J. Wang, and W. Fan, "Graphene oxide: an efficient acid catalyst for alcoholysis and esterification reactions," Chemcatchem, vol. 6, no. 11, pp. 3080-3083, 2014.

[23] X. Gao, S. Zhu, and Y. Li, "Graphene oxide as a facile solid acid catalyst for the production of bioadditives from glycerol esterification," Catalysis Communications, vol. 62, pp. 48-51, 2015.

[24] J. Cheng, Y. Qiu, R. Huang, W. Yang, J. Zhou, and K. Cen, "Biodiesel production from wet microalgae by using graphene oxide as solid acid catalyst," Bioresource Technology, vol. 221, pp. 344-349, 2016.
[25] Z. Wei, Y. Yang, Y. Hou, Y. Liu, X. He, and S. Deng, "A new approach towards acid catalysts with high reactivity based on graphene nanosheets," ChemCatChem, vol. 6, no. 8, pp. 2354-2363, 2014.

[26] S. Kundu and B. Basu, "Graphene oxide (GO)-catalyzed multi-component reactions: green synthesis of library of pharmacophore 3-sulfenylimidazo[1,2-a]pyridines," RSC Advances, vol. 5, no. 62, pp. 50178-50185, 2015.

[27] W. S. Hummers and R. E. Offeman, "Preparation of graphitic oxide," Journal of the American Chemical Society, vol. 80, no. 6, p. 1339, 1958.

[28] D. Lee, "Preparation of a sulfonated carbonaceous material from lignosulfonate and its usefulness as an esterification catalyst," Molecules, vol. 18, no. 7, pp. 8168-8180, 2013.

[29] V. C. Nguyen, N. Q. Bui, P. Mascunan, T. T. H. Vu, F. Pascal, and N. Essayem, "Esterification of aqueous lactic acid solutions with ethanol using carbon solid acid catalysts: amberlyst 15, sulfonated pyrolyzed wood and graphene oxide," Applied Catalysis A: General, vol. 552, pp. 184-191, 2018.

[30] M. S. Shafeeyan, W. M. A. W. Daud, A. Houshmand, and A. Shamiri, "A review on surface modification of activated carbon for carbon dioxide adsorption," Journal of Analytical and Applied Pyrolysis, vol. 89, no. 2, pp. 143-151, 2010.

[31] L. Ai and J. Jiang, "Removal of methylene blue from aqueous solution with self-assembled cylindrical graphene-carbon nanotube hybrid," Chemical Engineering Journal, vol. 192, pp. 156-163, 2012. 

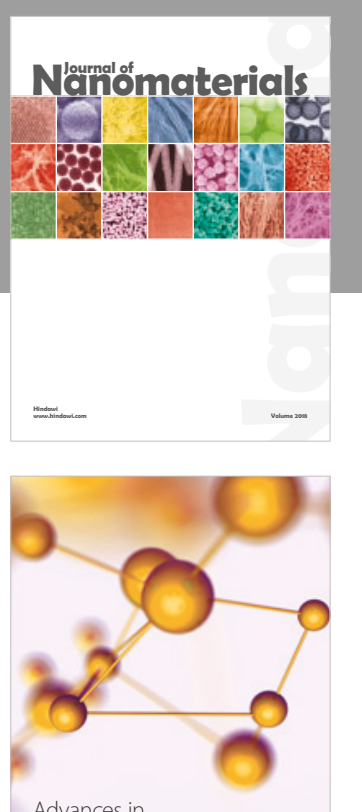

Physical Chemistry
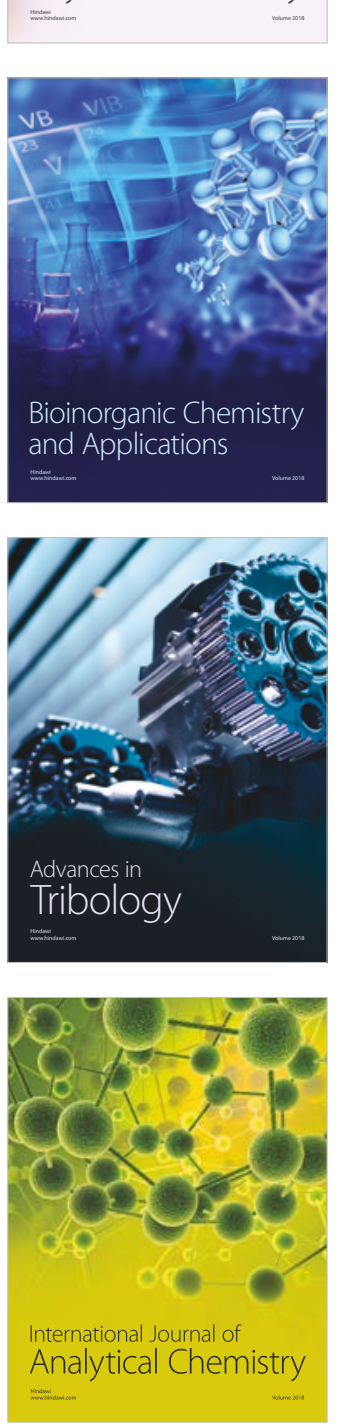

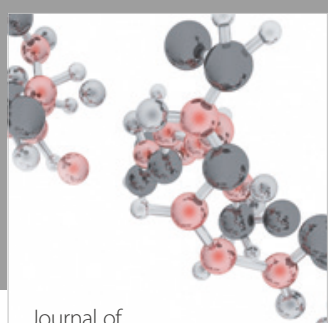

Analytical Methods

in Chemistry

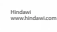

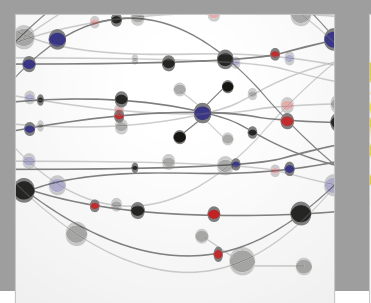

The Scientific World Journal

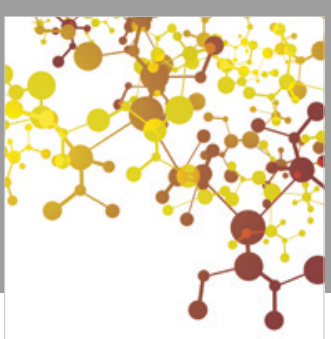

Journal of

Applied Chemistry
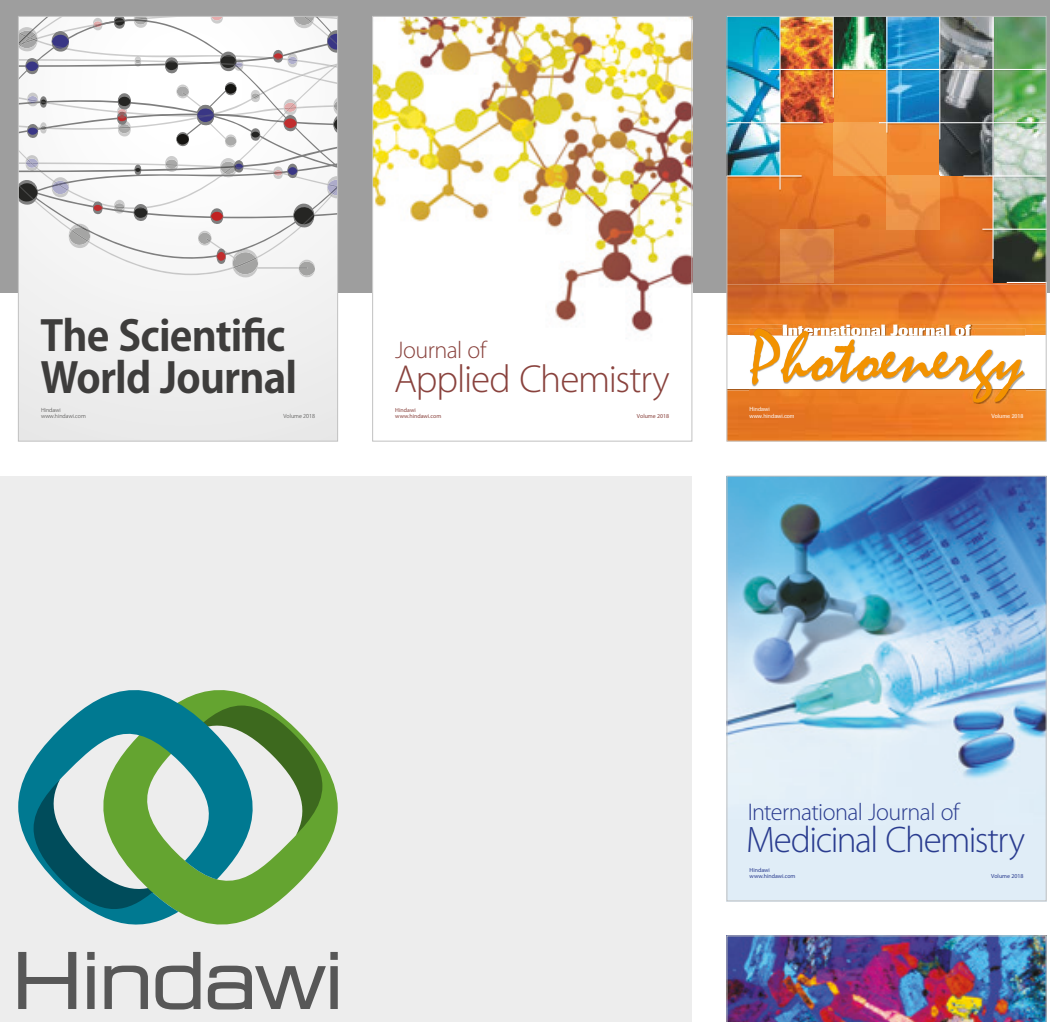

Submit your manuscripts at

www.hindawi.com
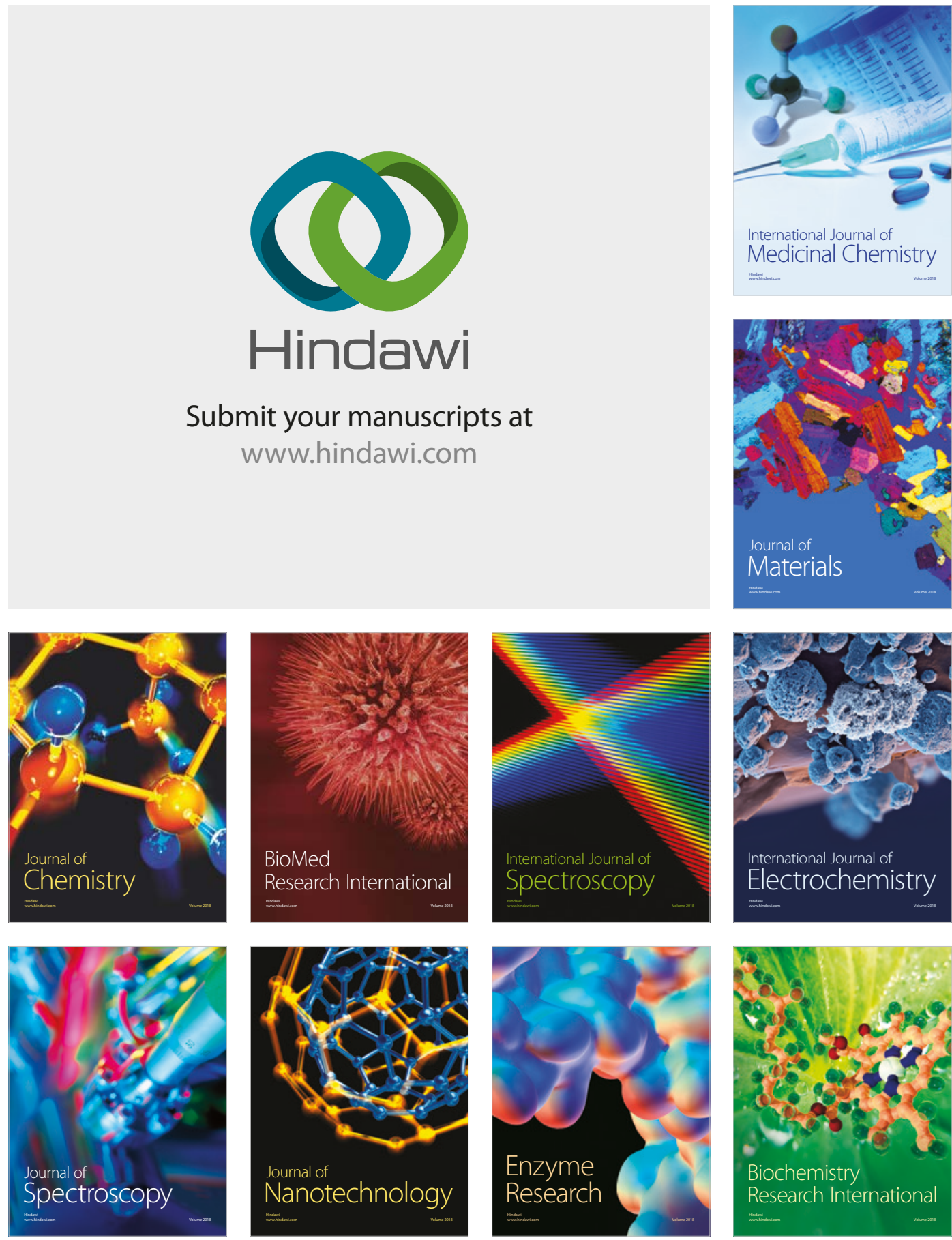
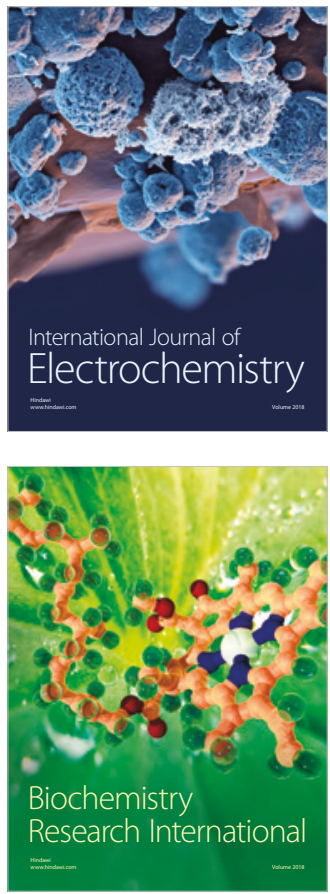